in long-standing persistent atrial fibrillation. J Thorac Cardiovasc Surg. 2020;160: 399-405.

2. Melby SJ, Zierer A, Kaiser SP, Schuessler RB, Damiano RJ Jr. Epicardial microwave ablation on the beating heart for atrial fibrillation: the dependency of lesion depth on cardiac output. J Thorac Cardiovasc Surg. 2006; 132:355-60.

3. Pruitt JC, Lazzara RR, Ebra G. Minimally invasive surgical ablation of atrial fibrillation: the thoracoscopic box lesion approach. J Interv Card Electrophysiol. 2007; 20:83-7.
4. McCarthy PM, Kruse J, Shalli S, Ilkhanoff L, Goldberger JJ, Kadish AH, et al Where does atrial fibrillation surgery fail? Implications for increasing effectiveness of ablation. J Thorac Cardiovasc Surg. 2010;139:860-7.

5. Miyagi Y, Ishii Y, Nitta T, Ochi M, Shimizu K. Electrophysiological and histological assessment of transmurality after epicardial ablation using unipolar radiofrequency energy. J Card Surg. 2009;24:34-40.

6. Sternik L, Kogan A, Luria D, Gilkson M, Malachy A, Levin S, et al. Box lesion in the open left atrium for surgical ablation of atrial fibrillation. J Thorac Cardiovasc Surg. 2014;147:956-9.
See Article page 399.

\section{Commentary: Pursuit of the electrically isolated box}

\author{
Richard J. Shemin, MD
}

The opportunity to surgically treat patients with longstanding persistent atrial fibrillation (AF) without a concomitant cardiac lesion is uncommon. Catheter-based ablation has been the preferred approach, but the results have not been good $(<50 \%$ freedom from $\mathrm{AF}$ at 1 year). For surgical ablation to serve as an alternative to catheter ablation, several important elements must be met. Improved efficacy is paramount; however, the reproducibility of the procedure, ease of performing the procedure, and adaptability of the device delivering the energy source to minimally invasive approaches are critically important to success. Thorascopic techniques have been developed, and bipolar or unipolar radiofrequency (RF) energy delivery devices have been adapted to less invasive approaches. Techniques with a range of variations have been described. The best techniques, MAZE lesion pattern, and documented efficacy in long-standing persistent $\mathrm{AF}$ require larger studies.

In this issue of the Journal, Harlaar and colleagues ${ }^{1}$ compare 2 different techniques and different energy delivery devices on the efficacy of restoring normal sinus rhythm (NSR). It is studied after a minimally invasive modified left-

\footnotetext{
From the Division of Cardiac Surgery, Department of Surgery, Cardiovascular Center at UCLA, David Geffen School of Medicine at UCLA, Los Angeles, Calif. Disclosures: Author has nothing to disclose with regard to commercial support. Received for publication Dec 2, 2019; accepted for publication Dec 3, 2019; available ahead of print Dec 20, 2019

Address for reprints: Richard J. Shemin, MD, 100 UCLA Medical Plaza, Suite 730, Los Angeles, CA 90095 (E-mail: Rshemin@mednet.ucla.edu).

J Thorac Cardiovasc Surg 2020;160:407-8 $0022-5223 / \$ 36.00$

Copyright (c) 2019 Published by Elsevier Inc. on behalf of The American Association for Thoracic Surgery

https://doi.org/10.1016/j.jtcvs.2019.12.013
}

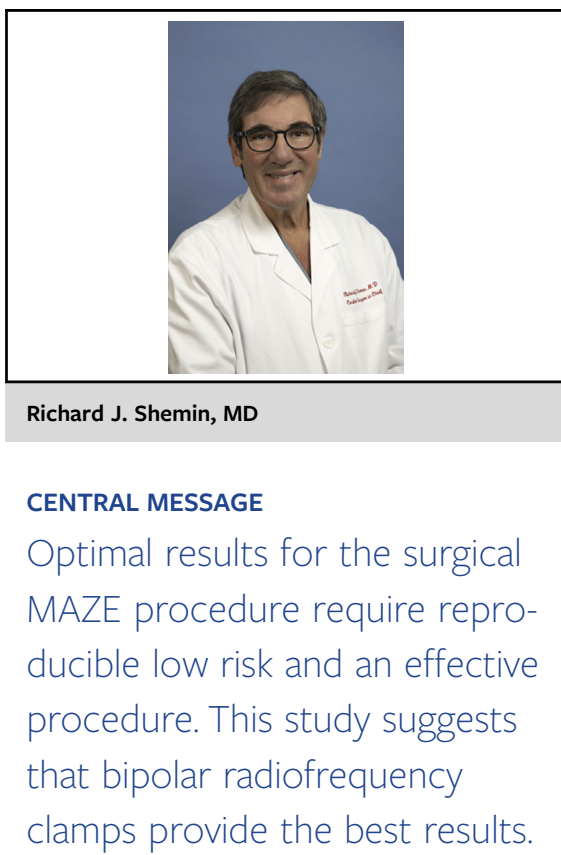

sided MAZE. Both approaches include bipolar radiofrequency ablation of the pulmonary veins in pairs. The roof and floor connection lines of ablation differ. These lesions were created by a RF clap in one group and with a unipolar irrigated RF device in the other group. More important was the number of energy source applications ( 4 with the bipolar clamp vs up to 20 with the unipolar device, ie, no clamp). This has implications for operative times. As expected, the "heat sink" of circulating blood in the no clamp technique is an issue.

To the investigators' credit, entrance and exit block mapping of both the pulmonary veins and the isolated posterior left atrial wall within the box was performed. Additional ablation was done if the isolation was incomplete. It should be noted that the potential for conduction recovery across a line of ablation is possible, due to stunning and recovery over time. Thus, intraoperative isolation documented by my mapping is not totally reliable. 
The data in this small study point to greater efficiency with the clamp technique. There is less time spent ablating the tissue, a greater rate of successful intraoperative isolation, and less need for late catheter-based mapping for gaps and ablation future procedures. The clamp technique is more likely to produce transmural and contiguous lines of ablation to isolate the pulmonary veins and posterior left atrial wall.

The surgical MAZE technique has the added value to the treatment by routinely excluding or removing the left atrial appendage using either a clip or a stapling device. The ease of use of these devices, complications, and relative costs are important issues not reported in this study.

The return to NSR was $100 \%$ at 3 months and $91 \%$ at 12 months in the clamp group, compared with $95 \%$ at 3 months and $79 \%$ at 12 months in the no clamp group. Perhaps due to the small numbers in each group, this difference did not achieve statistical significance. The need for repeat catheter ablation was twice as high in the no clamp group. Clearly, repeat electrophysiology studies in cases of failed surgical ablation to identify lesion line gaps and catheter ablation can be very efficacious. In addition, postoperative atrial flutter can be easily treated with catheterbased ablation creating a left atrial isthmus line or cavotricuspid line, depending on the mapping of the flutter circuit.

The literature on AF ablation efficacy and the return to NSR is confusing because of the varying types of analysis. Most commonly, studies report the percentage of the cohort in NSR on or off arrhythmic drugs at various time points (eg, 3, 6, and 12 months). The other common methodology is Kaplan-Meier analysis. This method of analysis is effective for such outcomes as death or stroke, which are "yes or no" events; however, AF can come and go. In addition, clinical benefits are discussed in terms of the "burden" of AF; for example, a patient with long-standing persistent $\mathrm{AF}$ is in $\mathrm{AF} 100 \%$ of the time. However, if a treatment improved a patient to the point that over a 1-year period, only 1 temporary episode of AF occurred at a 6-month follow-up and was asymptomatic, then this patient would be considered a treatment failure. From the clinician's and patient's viewpoint, this would be a treatment success! In this study and future reports of AF, editors should insist on standards for reporting outcomes, and so comparability is possible.

Longitudinal mixed-state modeling is emerging as the most appropriate modeling approach for analysis. In this study, time and surgical technique were fitted as fixed effects. Time was included as a categorical covariate, contrasting follow-up at 6 and 12 months with that at 3 months to account for nonlinearity of effect at log-odds scales. Time points represented rhythm status measured at the time of follow-up plus any recurrences detected in the preceding interval. A normally distributed withinperson effect is added to the model to account for within-person correlation in longitudinally observed recurrence of atrial arrhythmias.

In summary, the minimally invasive clap techniques for roof and floor ablation lines connecting isolated pairs of pulmonary veins (with a clamp technique) is an efficient operation requiring less future catheter-based ablation "touch-ups" and better return to sinus rhythm. Attention to the number of device ablations for each line of ablation and intraoperative mapping is essential.

An electrophysiology partnership is ideal. Patient selection and close follow-up as an "arrhythmia heart team" will increase the likelihood that patients will be offered a surgical approach to treating long-standing persistent AF.

\section{Reference}

1. Harlaar N, Verberkmoes NJ, van der Voort PH, Trines SA, Verstraeten SE, Mertens BJA, et al. Clamping versus nonclamping thoracoscopic box ablation in long-standing persistent atrial fibrillation. J Thorac Cardiovasc Surg. 2020; 160:399-405. 